\title{
Identifying Model for Decision Making Process in a Collaborative Manufacturing Network Environment
}

\author{
Mohammad Rizal Firmansyah,, ${ }^{\mathrm{a}, *}$ Wihdat Djafar, ${ }^{\mathrm{b}}$ \\ aDepartment of Naval Architecture, Engineering Faculty, Hasanuddin University, Makassar. Email: mr.firmansyah@unhas.ac.id \\ bepartment of Naval Architecture, Engineering Faculty, Hasanuddin University, Makassar.
}

\begin{abstract}
In order to be competitive through globalisation and free trade agreements, Small Manufacturing Enterprises must provide a high quality products at a competitive price at the right time. But inadequate resources of the enterprises have prevented them to remain competitive. Therefore they need to innovate and find new ways to overcome these challenges. Collaborative Manufacturing Network (CMN) is a way forward to address these challenges. However, the process of collaboration is not a simple process. Instead, it is a complex and very dynamic process since there are many factors involved that need to be considered for the establishment of a successful collaboration. Many researches have been conducted in this area of CMN, but there are still numerous unsolved problems identified. Decision making issues and formulating business collaboration model in a context of CMN are two such issues. This research tries to identify the problems faced in a CMN environment, stress on the importance of building a model based on the consideration of aspects involved in a CMN and then identifying model for decision making process in a CMN Environment.
\end{abstract}

Keywords: Collaborative manufacturing network; decision making process; small manufacturing enterprises

\section{Introduction}

In this global business environment, manufacturing companies are facing competitive strength even greater than before [1]. Manufacturers are forced to provide products with high quality as well as low prices in the right time [2]. Challenges for a manufacturer in today global environment includes short product life cycle, product varieties, minimal inventories, concurrent processing of different products, short delivery times [3], well informed and demanding customer [1], mass customization, and short lived market opportunities [4]. That is why manufacturing companies need to continuously make an innovation and adapt their business to survive and meet the fast changing market environment. This has influenced the way of business operates and interoperates with other enterprises [5].

There are several solution have been offered by some researchers for above challenges which are improving product cycles, reducing cost, communicate and work

*Corresponding author. Tel.: +62-812-3745-4156

Jalan Poros Malino km. 6, Bontomarannu

Gowa, Sulawesi Selatan, Indonesia, 92171 concurrently in the enterprise network [1], working together and establishing partner in a collaboration network [3], internationalisation, operate in different country or develop global strategies for operation coordination [2]. It seems that coordination of activities in a network become urgent to respond the fast changing environment $[6,7]$. Clarke [8] state that knowledge and expertise held by others is often required in order to operate effectively in this fast changing environment.

Collaboration is a way forward for manufacturing enterprises to solve their constraints. There are several reasons for companies to conduct business collaboration and the most important ones identified by Hansson in [9] which are; 1) Collaboration as strategic positioning, 2) Learning and exchange of experiences, 3) Possibility to develop and deliver more complex products, 4) Synergy factors in technology and product development, and 5) Economic factors, such as risk sharing, investments, etc.

The driving force for collaboration is stated by Noori and Lee [10] as digitization, the internet development, and high speed data networks. This can be used for addressing many issues from design to distribution. The collaboration is expected to gain a competitive edge $[11,12]$ of manufacturing enterprises through increasing their skills, capabilities and capacities [13], and focus on their core 
competencies and sharing their resources [10, 13]. It is needed to sustain in this environment $[14,15]$. Companies now tend to engage in a partnership [13]. For some relatively small manufacturing companies, it is important for them to collaborate to increase their scale.

Collaboration could facilitate the company's growth through [16] fostering networking among vary manufacturing industries, developing business activities into national levels, facilitating industry participation, facilitating industry collaboration with Research Centre's and building industry capacity.

Collaborative manufacturing network $(\mathrm{CMN})$ is an approach that can be used to solve those challenges. Johansen, Comstock and Winroth [17] see CMN as an "extended enterprises consisting of several companies that cooperate in a project resulting in a manufactured product, where each company has expert competencies in one or several areas". It can be seen that companies joined in a CMN have bigger opportunities to increase their market niche [18]. However, the process for collaboration is not a simple process. Instead, it is a complex and very dynamic process since there are many factors involved that need to be considered for the establishment of a successful collaboration. Besides, the interaction and relationship among participants in CMN is very complex as well.

The establishment of interconnection among enterprises become requirements of a $\mathrm{CMN}$ in order to [5]: 1) learn from each other and exchange experience, 2) strive towards mutual objectives and developed complementary products and services, 3) explore development of complex products and services that are beyond the capability of a single company, 4) identify synergies in capabilities such as technology and product development and 5) share risk and investment. However, there are some other requirements for manufacturing enterprises in order to build a successful integration of activities [10] which are 1) addressing multi plant organization, 2) handling supply chain and distribution, 3) integrating financial analysis, 4) providing real time forecasting, 5) supporting manufacturing execution systems and finite scheduling, and 6) providing executive information and decision-making tools.

To fulfil the requirements, many companies have built a complex system that facilitate the decision making process but most of the system are integrated vertically. In the decision making process connection among all decision components need to be integrated horizontally and vertically. This connection needs a very complex structure as well as requires large investment for the establishment. Unfortunately, most of the small manufacturing companies have limited financial resources and do not have such technical abilities to establish such a complex structure.

In order to build a supportive model that can be used by small manufacturing companies, several issues need to be considered. The production distribution among companies involves in a collaborative manufacturing [9], information and communication technology [19], the selection of partners, the expansion capabilities of the respective participating companies for managing collaboration [5], [20], the worldwide distribution of the participant companies, the virtuality of the participating companies [21], the different uses of software tool of respective companies and understanding of the pattern of communication and information flow across different participants [19].

Trust among companies involved in collaboration need to be enhanced as well since the collaborative arrangements are based on identified competencies [22]. Many of the business process should be open to all participants without being fear of being taken advantage by others. This can be achieved if the participating companies understand the comprehensive aspect of their contribution, appreciate how their business information is to be used and understand how this risk is managed in respectful manner.

There are many factors and issues involved on the decision making process in a CMN. A range of production, managerial and economic decision confront a CMN including [23]: 1) where to manufacture, 2) sharing of design and engineering aspects among members of CMN, 3) optimal scheduling logistics of CMN, 4) dependency versus independency of manufacturing in a CMN, 5) how to perform business forecasting for the network, 6) who receives an order and how is it entered into shared systems, 7) purchasing issues among partners, 8) conflict resolution and risk management, 9) sharing confidential information among partners and 10) fostering trust across diverse organisational culture.

Most of these fragmented information and decision processes are controlled by various members in a CMN. Making a holistic decision model in this complex decision making environment increases the difficulty for the participants in a CMN to provide a complete solution to the customers. Coordination in a CMN which is includes a complex myriad of partners spanning several countries and even continents, is not understood yet [17].

The understanding of such factors is essential for the establishment of a comprehensive model of decision making process. Further, the relationships of dependent as well as independent participants in collaboration need to be mapped in order to model the business collaborations in the context of CMN. This is very significant for manufacturing companies since there are tendency for them to make collaboration without a clear understanding of the issues and constraints which could lead to increased risk on business failure.

\section{Dependent and Independent Participants in a CMN}

Basically, participants in a collaboration manufacturing network can be divided into internal and external participants. Internal participants are participants who exist within a company while external participants are participant from external company. The relationship among 
participants can be dependent or independent to each other, within company (internal participants) and/or among external company (external participants) [24, 25]. Dependency of the participant relationship depends upon the type of collaborations they have involved [2].

There are several forms of collaborations and each form consists of different participant. Generally the most common form of collaboration is between system integrator (SI) and supplier [9]. Danilovic and Winroth [9] explain that the relationship of SI and supplier can be formed in three models which are the traditional model, the japanese model and the advanced model. Each model is differentiated based on the involvement level of the supplier in the system integrator.

The traditional model, where suppliers are involved after the design is completed, and technical specifications determined. In this model, system integrator restricts access to the information design. In the Japanese model, the involvement of suppliers are in the early stage of the concept phase before design is determined while in the advanced model', the supplier involvement is balance between the benefits of the Japanese model with access to new technical ideas until the final definition is determined. In the SI and supplier relationship, Danilovic and Winroth [9] describe external participant relationship as a system integrator (usually big company) and several suppliers. The relationship among participants is dependent each other.

Different form of collaboration is proposed by Montreuil, Frayret,and D'Amours [26] which includes more detail different participants. They describe the collaboration form into network manufacturing (NetMan) which consists of several manufacturing centres. Each of these manufacturing centres can be in the form of external business or internal business. External business can be external supplier or subcontractor while internal centre can be manufacturing cell, a process centre, a department or a maintenance centre. Each of these internal businesses acts and operates as a manufacturing business but still in coordination with their parent business. In this NetMan model, there are internal and external participants involved. External business can be regarded as external participants while internal business can be regarded as internal participants.

Similarly, Mesa International [27] describes the types of participants involve in the collaborative manufacturing as external and internal participants. External participants include customer, distributor and channel partners, material and sub-product supplier, outsourced or contract manufacturers, logistics partners for distribution, warehousing and transportation and service provider. While internal participants within each company includes multiple departments and division supported the manufacturing process. The agility to deliver accurately of product (customized or new product) requires synchronization among manufacturing activities in the network [27]. This synchronization performed by internal participants consists of design section which is working together with other sections (marketing, sales, etc) including partner design, production groups and customer.

Montreuil, Frayret, and D'Amours [26] describe three version of network manufacturing which is highly distributed manufacturing network, manufacturing network with bus realization centre, and manufacturing network with bus realization centre and centralized supply centre. Each alternative involves dependent and independent participants. Several centres in each alternative act as an independent participant while the other as dependent participants. ARC [28] explains the model of collaborative manufacturing management. In this model, it is described internal participants (functional area in a company) and external participants (external company entities). It emphasises the importance of internal participants to collaborate internally which mean that the relationship among internal participants need to be considered. The relationships between internal and external participants are also recognised.

\subsection{Relationship of dependent and independent participants}

The importance of relationship of dependent and independent, external and internal participants in a CMN has been described by several researchers. Firstly, it is need to define participants relationship in a collaboration network [24, 25, 29, 30, 31, 32]. Then trust and commitment in this relationship are required to link their activities and resource ties and to describe interdependency of internal and external participants, determine performance network and identify additional opportunities for joint project $[8,11,25,33,34]$. This also can be used to gain competitive advantages in cost savings, technological innovation, shorter lead times, joint marketing program and shortened response time [35] under the competitive pressures. This is important in determining long term relationship $[26,31,36]$.

This long term relationship need strong business interdependencies which is relies on information exchange, collaborative planning and operation management and business rules of the game [11, 30, 35]. In managing the relationship, there are key successes factors need to be considered [11] which include; quality, reliability, flexibility, transparency, and process intervention, cooperative practices, learning from problems and commitment to quality and regular meetings concerned with strategic planning and development, and included quality evaluation, costing, forecasting and scheduling.

Kanter in [11] argues that the most productive relationship will achieve five types of integration which are; strategic integration - enable discussion among top leaders regarding respective company goal and economic change, tactical integration - enable middle managers to work together to develop plans for specific projects, operational integration - enable solution to carry out daily 
work, interpersonal integration - enable building necessary foundation for sustaining the future of the relationship, and cultural integration - enable people involved in the relationship to have the communication skills and cultural awareness to bridge inter-organisational and interpersonal differences.

Choy, Lee, and Lo [1] described two forms of the relationship of participants in a collaboration which are customer relationship management (CRM) and supplier relationship management (SRM). CRM is "a process by which a company maximizes customer information in an effort to increase loyalty and retain customers' business over their lifetimes". This CRM is about finding, getting and retaining customers to build long term and profitable relationship. SRM is a relationship that can be used in supplier selection for increasing the competitiveness of a manufacturer through three establish mechanisms which are; 1) Support of improved business processes across the supply chain, 2) a next-generation architecture that can handle multi-enterprise processes, and 3) facilitation of rapid product cycles and new product introduction.

Johansen, Comstock and Winroth [17] divides relationship in a collaboration network into four categories which are upstream vertical relations (each company has suppliers), downstream vertical relations (relationship with customer or buyer), direct horizontal relations (relationship between the company and/or organization and other industry players), and indirect horizontal relations (relationship with industry outside its own industry segment). The relationship is different from the Palakshappa and Gordon [37] views. They categorised relationship into high or low technology use, cumulative or complementary resource contributions, international or domestic partners and above or below average performance.

The simpler categorization of relationship is stated by Valespir and Kleinhans [38]. They differentiate the relationship among participants as make or buy relationship. Palakshappa and Gordon [37] explained that the relationship in collaborative network may differ in terms of their legal structures, governance arrangements and the number of participating organisations which may include many other participants in research and development, production and manufacturing, sales and marketing, or a number of other activities.

Montreuil, Frayret, and D'Amours [26] explain the other form of relationship among participants in a network manufacturing (NetMan) centres. They said that all relationship must be built on a mutually agreed conventions and agreements. The convention arranges coordination as well as the information flows from each centre respectively. The contents of the conventions are deal with the rules of how to perform and modify order among center.

Perrin et al. [5] described a Synchronization Point (SP) model which can be used for supporting collaboration and cooperation for multi enterprises processes. The model takes advantages of workflow management systems and groupware systems. With this model participants can work together by only need to agree cooperation rules according to contract specification and the SP model will provide all information needed for the cooperation. The advantages of this SP model is its ability to be updated during work progress as well as to evaluate the process against a given specific criteria.

\subsection{Issues in the relationship of independent and dependent participant}

Anumba et al. [19] has introduced a concept of a multi agent system (MAS). The MAS can support the interaction among different participants that usually conducted in a collaborative design. They argued that the system can be used for facilitating collaborative design in a distributed construction environment. The concept can also be used for ease multidisciplinary perspective, tool and techniques. However, the systems still need to be developed as some issues in the relationship between participants are not covered yet. Issues include is mechanism for the integration of agents with legacy CAD and IT systems.

Issues regarding distances in a relationship are stated by Miralles in [9]. He said that there are four types of distances in which companies can have in their relationship. They are social distance, cultural distance, technological distance, and time distance. Further, they explain that social distance is whether the companies familiar each other with their way of thinking, cultural distance is whether they are different in term of values and norms, technological distance is whether they are different in terms of technological development while time distance refers to whether time for make product delivery as well as payment. These distances can be reduced by increasing social interaction among companies.

\subsection{Map of the relationship in the dependent and independent participants}

Relationships between buyers and suppliers in manufacturing industries have changed substantially over the past few decades [35]. The successful collaboration among participants in a CMN depends on the degree of closeness in the relationship (Prasad in [9]). There are many participants involved in collaboration and each participant with their production characteristic need to relate with other in order to get optimum benefit of such collaboration. Besides, there are many types of collaboration with their respective relationship among participants. In order to have successful integration, all components involve in a collaboration have to be considered and managed [39]. Coordination aspect is seen as important factor to be considered in the mapping of relationship as it relate interdependency among business process [33]. 
Palakshappa and Gordon [37] stressed the importance of how the relationship is conducted. The purpose of collaboration need to be analysed as it determined the successful collaboration. Further, they said that it needs to differentiate whether a company's conduct in collaboration on their own or as a result of public policy initiatives as they will result on a different benefit. Participants in collaboration manufacturing network consist of manufacturing nodes which are connected by material, information and process flow. This relationship need to be mapped as it determines the success implementation of collaboration [5, 28].

It can be said that for the successful of collaboration, there are some aspects need to be understood. First of all, types of collaboration, then how many participants involved in the collaboration and how they connected each other in terms of their production characteristics. The relationship among participant is important to understand. Hence the identification of all participants to be joint in a CMN needs to be known as well as their respective relationship [40]. Further they said that the understanding of supplier and customers must also include the customers' customers and the suppliers' suppliers.

According to Shi and Gregory [41], coordination between market requirements and corporate strategies influence all aspects in the collaboration including manufacturing network and internal participants. Pattern of coordination must be decided before collaborative network is designed. This pattern and other aspects are important for designing collaborative manufacturing network [41]. Further, Yam, Chan and Chung [40] said that it is very important to understand that all participants to get involved in a manufacturing network.

The successful collaboration among participants in a CMN depends on the strength relationship among them. Mapping the relationship among participants involved in a $\mathrm{CMN}$ is crucial in order to better understand the connection of each participant. Huff in [37] described that mapping technique have been used to develop a visual representation of elements which influence performance in the relationship. Further they explained that mapping provides a good trigger for memory and will help reveals gaps in information. In a mapping of relationship, there are three things need to be considered which are information, material and process flow [28]. Palakshappa and Gordon [37] said that mapping will allows us to assess participants' relationship and their performance in the collaboration.

\subsection{Classification of participants and their relationship}

There are some possibilities regarding participants and their relationship. Participants both can have dependent and independent relationships. In the describing the relationship, it is much easier if the relationships among participants are being put in the house of relationship (Fig. $1)$.



Figure 1. House of relationship (adapted from Evans and Lindsay [42])

The idea of this house of relationship is adapted from the house of quality [42]. In this house, a set of matrixes is used to relate the internal participants and external participants and between external and internal itself. Building the house consists of five basic steps which are 1) identify internal participants, 2) identify external participants, 3) relate internal participant to the external participants, 4) relate participant in the internal participants and 5) relate participants in the external participants.

The development of this house of relationship can be illustrated below.

Step 1. Identify internal participants. Internal participants are participants who exist within a company that relate directly and indirectly with external participants in the collaboration. Participants who relate directly with external participant are called dependent participants while participants who relate indirectly with external participants are called independent participants. These kinds of participants can be system integrator (the company itself), manufacturing cell, a process centre, a department, a maintenance centre or any functional area in a company. Beside the relationship with external participants, internal participants also can have relationship among them.

Step 2. Identify external participants. External participants are participants external company that relate directly or indirectly with internal participants. These kinds of participants can be supplier, customer, distributor and channel partner, material and sub-product supplier, outsourced or sub-contractor, logistics partners for distribution, warehousing and transportation and service provider. Similarly, the relationship is not only with internal participants in a company but also among the external participants itself.

Step 3. Develop a relationship matrix between internal participants to the external participants. Internal participants are listed down the left column while external participants are written across the top. In the matrix itself, symbol indicates the relationship. The purposed of the relationship matrix is to show whether the relationship 
between external participants and internal participants are dependent, independent or no relationship.

Step 4. Relate participants in the internal participants. In this step, relationship between internal participants is showed. The relationship is also represented in a symbol which show whether the relationship is dependent, independent or no relationship.

Step 5. Relate participants in the external participants. This step is conducted in the same way in step 4. Only that it relate between external participants itself.

There are several types of collaborations and each type involves different participants. Several relationship models are described to show the use of this house of relationship. Danilovic and Winroth [9] describe participants in his model as external and internal. Internal participant is described as system integrator (SI), usually a big company which has several suppliers which act as external participants. The relationship among these participants is dependent between SI and supplier but independent and possibly dependent among suppliers. The relationship among these participants can be described in the house of relationship below (Fig. 2);

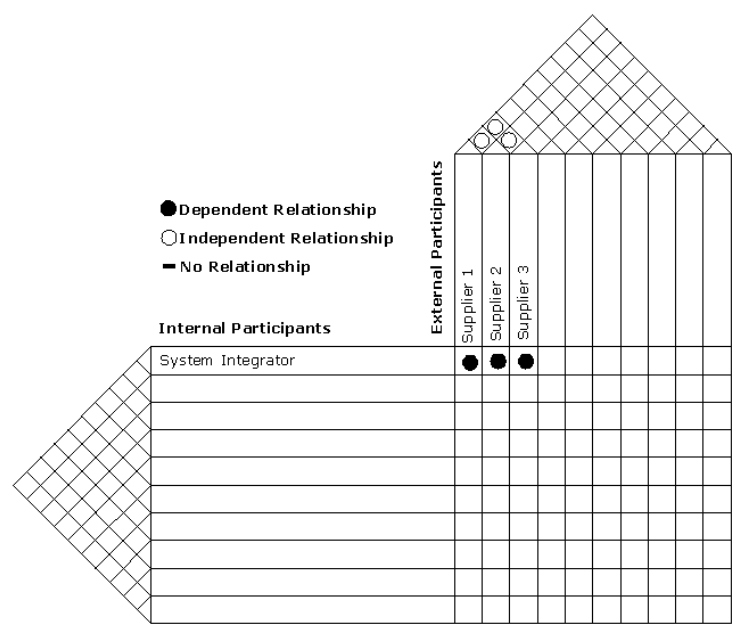

Figure 2. Mapping of relationship for Danilovic and Winroth model [9]

The relationship between suppliers can be dependent or independent depend on whether between one supplier and other supplier has direct relationship among them. If they have direct relationship, it means that they have dependent relationship and vice versa.

Different form of collaboration is proposed by Montreuil, Frayret, and D'Amours [26] who includes more detail of participants compare to Danilovic and Winroth [9] model. They described the collaboration form into network manufacturing (NetMan) which consists of several manufacturing centres. Each of these manufacturing centres can be in the form of external business or internal business. External business can be regarded as external participants which includes external supplier or subcontractor while internal centre which can be as internal participants includes manufacturing cell, a process centre, a department or a maintenance centre. The relationship among these participants are described in the house of relationship below (Fig. 3);

The more complete description of external participants is explained in Technology Partnerz [43] which includes supplier, customer, media, shareholder, employees, creditors, unions, governments, regulators, and market analysis. For internal participants, the most complete description is discussed by Timings [44] which includes marketing, design, procurement, material preparation, processing, assembly, finishing, packaging, quality control. Not all identified participants here are important and used in the collaborative manufacturing process. For examples, in the external participants, media, employee, creditors and unions are not too important in the manufacturing process.

These participants are regarded not important as from the author point of view, they are not directly and indirectly involve in the manufacturing process. In fact, they have no any relationship with manufacturing process activities.

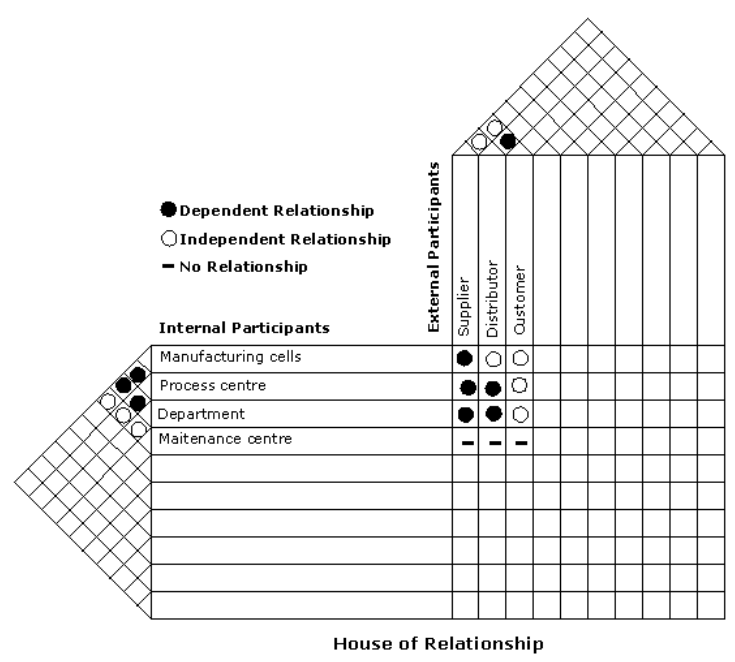

Figure 3. Mapping of relationship for Montreuil, Frayret and D'Amours (2000) model [26]

The more comprehensive identification of external and internal participants which is involved in the collaborative manufacturing network can be described as follows; external participants includes supplier, customer, distributor, subcontractor, regulator and government while internal participants includes marketing, design, procurement, material preparation, processing, assembly, finishing, packaging, quality control.

Mapping of these relationships can be conducted using the house of relationship as follows (Fig. 4); 


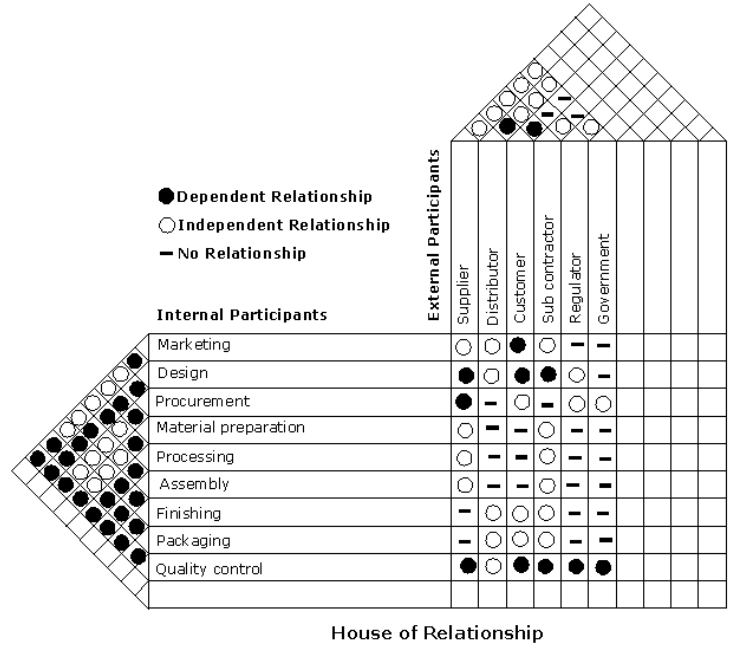

Figure 4. Mapping of relationship for proposed CMN model

It can be seen from these cases of participants and their relationship that as long as all participants (internal or external) which involve in the collaboration manufacturing network can be identified, then analysis regarding their relationship can be easily conducted using the house of relationship. Although the more complete identified participants, the more complex their relationship matrix is. Any issues regarding the relationship must be considered in this mapping process.

\section{Issues in decision making process}

The decision made to be involve in a globally network collaboration will determine the competitiveness of a company. Factors that need to be considered in this decision-making process are production, marketing, design and development. Cil, Alpturk, and Yazgan [20] includes social, environment and economic concerns in the consideration for decision making process. Forecasting demand is one other factor that influences the decision making [45]. There are several systems have been developed in order to facilitate the decision making process in a collaborative environment.

Courtney [46] described the flow of conventional decision making process as follows. First is problem recognised and defined. After that alternatives of solution are generated and by using model development, alternatives of solution being analysed. Then the best solution can be selected and implemented. This process keep continued in a loop of decision making process. Based on this simple decision making process, Courtney [46] developed group decision support systems (GDSS). The development is forced by the change in the collaboration network where production unit which is previously operated separately become an integrated production and by the changes of participant number and size from dispersed area. This is also influenced by the behaviour change in collaboration network. This new system enables brainstorming, idea evaluation and communication to support team problem solving. The establishment of executive information systems extend the possibility of this system to include corporate level decision making process [46]. For making decision making smarter support, Courtney [46] included a model management system and knowledge based decision support system which is based on artificial intelligence and expert systems into GDSS. The process of decision making in this new approach is start from the recognition and definition of problems but instead of analysing technical perspective, the process consists of developing multiple perspectives. Perspective then synthesized and translated it into actions as a result of decision making [46].

Further, Courtney [46] described several form of organization in decision making. This organization can be in the form of units within an enterprises or temporary groups to solve decision problems. They categorized the organization into four which are;

- The Leibnizian organization. This organization can creates knowledge to make inferences about cause and effect of a relationship.

- The Hegelian organization. The decision making is based on conflict. Decision makers encourage the development of alternative points to solve a decision problem. The solution is chosen for solving the problems.

- The Kantian organization. The decision making is made from selection of many alternatives which is generated by organization. The problems is analysed from a technical perspectives. This approach requires knowledge management which are capable of maintaining problem data and support the development alternatives for explaining the data.

- Singerian organizations. This organization views the world as a holistic system, in which everything is connected each other. Assumption should be made by identifying group or anyone affected by the decision as well as 'true' assumption which will be based on the decision actions.

Courtney decision making then developed into group decision support system (GDSS) by Cil, Alpturk and Yazgan [20]. This development was conducted in order to cover the complexity of social function in decision choice. This social function consists of cultural, organizational, personal, ethical and aesthetical. This system consists of web technology, a group decision making (GDM) process, a large number of multi-criteria decision making methods and social function. The need for GDM currently is even greater than before. This is because the tendency of company to involve in collaboration which is result in the complexity of business relationship. The complex relationship adds the number of organization and decision makers that involve in the decision process. This situation become more complex as there is greater online access to multiple external information sources besides the decreasing time needed to make a decision [20]. This GDSS system supports a group working in an unstructured 
problem and can support discussion oriented task in a group decision making [20].

Another system of decision making in a collaborative environment is proposed by Lee and Lau [47]. They designed a multi-agent modelling which can be used in a distributed information system applications. Further, they explained that this system can be used for modelling dispersed manufacturing network which can connect variety of manufacturing company on a global basis. Companies involve could be geographically separated in terms of allocation, coordination and monitoring of administration tasks. This model has an ability to facilitate the efficient performance of task allocation to the most appropriate company. Intelligent agents are used in this model to monitor the information flow and the allocation of task among participants in a network. The authors argue that the model developed can be used for various purposes, including decomposing jobs into fundamental tasks and design and creation of intelligent agents to optimize task sequence across distributed network.

An agent based systems are also suggested which can be used for make a decision locally according to local knowledge [19]. While the importance of understanding the factors involved in the decision making process is stressed by Danilovic and Winroth [9]. They composed four big questions into of 'what' is integrated, 'who' participating in the network, 'when' such participation and integration needed and 'how' the integration securely in a mechanism.

The decision making process issues in collaborative network environment involves on how to design an approach that can facilitate the decision making process while considering all factors of decision making. Lee and Lau [47] said that in their developed model which is multiagent approach for handling administration matters among companies in the network, factors for refining central management systems still need to developed in supporting the fully integration of the system. On the other hand, the importance of community and collaboration was emphasized by Courtney [46] though conflict can emerge in any part in the network. This conflict must be managed and dealt with it so that new decision making environment are needed as the expansion of current decision making system and knowledge management [46].

\section{Business model collaboration in the $\mathrm{CMN}$ context}

The extension of complexity of collaborative network which is varying in the degree of integration is not described yet. The most important reasons identified behind this [9] which are 1) creation of procedures and organizational routines enabling a high degree and high intensity of integration, and 2) design of a supportive decision-making structure. They further explained that it is very important to understand the characteristics of organization behavior in order to better design network setting in term of what is integrated, who is participating in networks, when such participation and integration is needed and how desired integration is to be secured. The other factors that influence the difficulty in designing a comprehensive framework for collaborative network are the lack of definition of complex business model collaboration which considered the levels of integration. Therefore it is important to define first the complete business model of collaboration before designing the framework for such comprehensive collaborative network.

Model of CMN proposed by Lin [48] will be suitable for development by considering relationship mapping in the previous section. In his model, collaborative partners of small manufacturing enterprises are categorised into three groups which are customer, suppliers and contractors. In this new proposed model, partners of SMMEs consist of four groups which are customer, suppliers, subcontractor and distributor. In addition, there are four collaboration network identified in the CMN itself which are collaborative marketing, collaborative design, collaborative procurement and collaborative production. Each of these four collaborations conducted only for their designated goal and CMN combine all these four into one single of collaboration. All these collaboration can be conducted by two or more participants companies.

The design of business collaboration in CMN context is showed in Fig. 5. It can be seen from this figure that group of customers have relationship with group of sub-contractor, group distributor, collaborative design and collaborative marketing. While group of sub-contractor have relationship with collaborative design beside with group of customer. Group of distributor have relationship with customer and CMN itself while group of supplier have relationship with collaborative design, collaborative production and collaborative procurement.

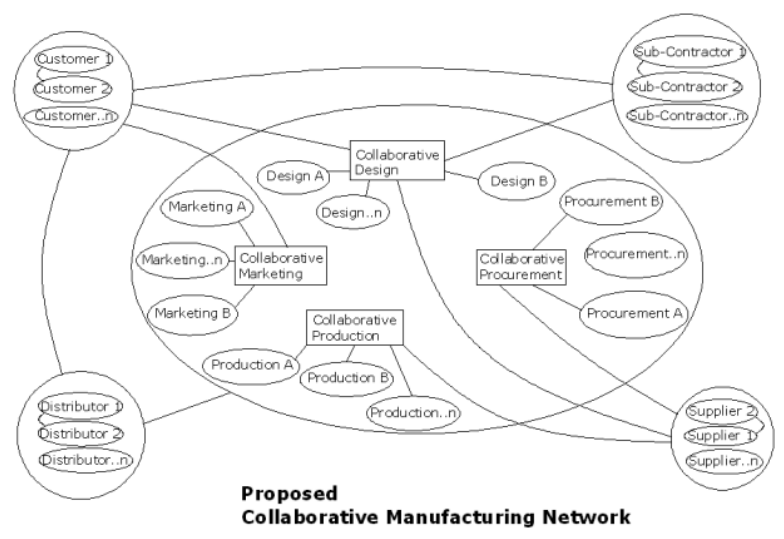

Figure 5. Busines collaboration model in the context of CMN

\section{Identification of an integrated model of decision making process in $\mathrm{CMN}$}

It has been discussed that there are several issues regarding decision making process in collaborative manufacturing. Many factors are need to be considered in order to facilitate the decision making process. Several approaches have been developed but there are still factors need to be included in the process. Factors that need to 
considered in the design of decision making for CMN are manufacturing, logistics and servicing process should be planned on the basis of massive, real time and quality information, participants should be able to make their own decision and taking their own initiative, interaction among centre should be supported by electronic forms of data interchange and by using new information technologies and information coordination needed for massive and complex exchanges of data.

A complete model of decision making process in collaborative manufacturing environment has been developed by Courtney in Lin [48]. This decision model was developed based on Simon's four phase decision making model in Lin [48]. In the Courtney model, there are four stages for the systematic decision-making process which are; collect intelligence, develop perspective preference and mental model, design decision model and evaluate choices and implement decision outcome [48]. This decision making model is depicted in Fig. 6.

Further, Lin [48] discusses the stages in this model. First is intelligence collection. This intelligence scans the manufacturing environment within the CMN and identifies deviation between actual performance and the respective goal. Any deviation means an indication of a problems and decision is needed. The main function of intelligence are setting business and manufacturing performance goal, identifying decision problems, establishing decision problem ownership and constructing formal problem statements.

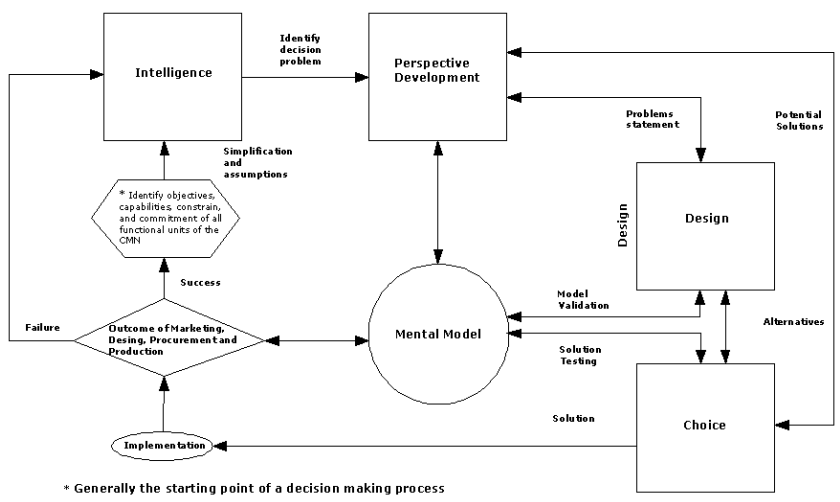

Figure 6. Systematic decision making process for GDSS. Adapted from Lin [48]

Next stage is development of perspective preference and mental model. The development is based on the expertise contributions of each manufacturing entities and these contribution bring new perspective to the creation of goals, alternatives and constraints. The understanding of manufacturing problems and participants perspectives on the problems form a complete mental model that suggest what kind of information and data should be analysed, to what extend and with which method. This mental model is evolved as more perspectives developed. After that, stage of design decision model and evaluate choice is discussed.
In this stage, design phase focus on the simplification of manufacturing environment in CMN and conceptualising decision problems in order to developing model that can analyse alternatives for decision solution. The choice phase in the mean time, compares all potential solution based on the decision model and justifies organizational resources for implementation recommended solution. The stage discuss is implementation of decision outcome. In this stage, implementation means to physically execute manufacturing activities in accordance to the recommended outcomes.

The identification of comprehensive decision model of CMN which consider all participants in the network is based on the Courtney in Lin [48] decision model. From the definition of proposed collaborative manufacturing network model in the previous section, it can be described that the CMN model consists of several collaboration which are collaborative marketing, collaborative design, collaborative procurement and collaborative production and CMN it self (Fig. 7). All this collaboration is involved in the new decision making model for collaborative manufacturing network.

In this extended decision making model, it also consist of four stages for the systematic decision-making process which are; collect intelligence, develop perspective preference and mental model, design decision model and evaluate choices and implement decision outcome. The differences with Courtney model are in the extended model, each stage consist of four collaborative items which is marketing, design, procurement and production. The differences influence the decision making process in each stage.

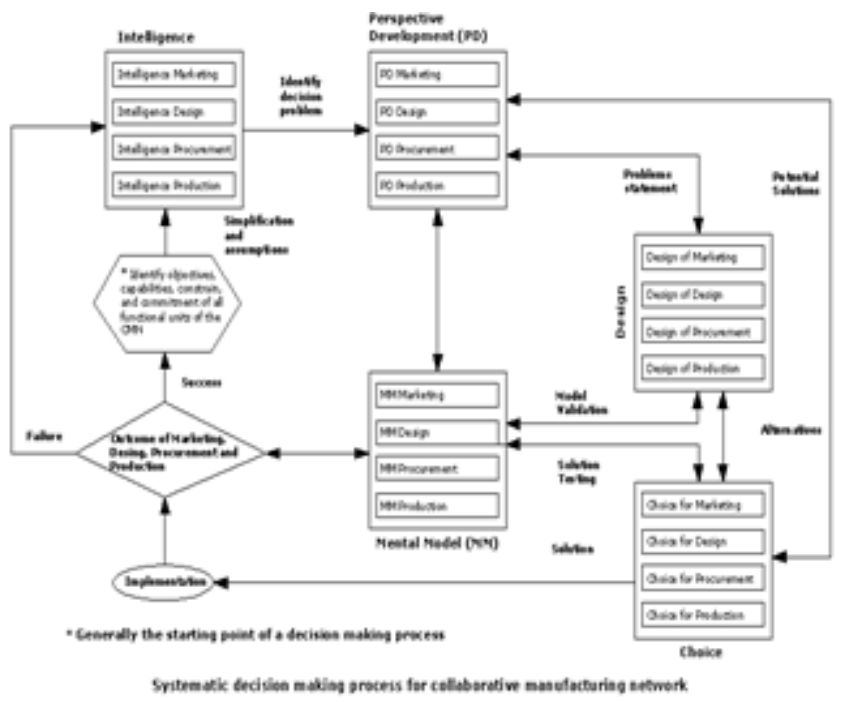

Figure 7. Extended systematic decision making model for collaborative manufacturing network. (Adapted from Lin [48])

First is in the intelligence collection. In this intelligence stage, scanning the manufacturing environment within the CMN are conducted four times which is in marketing, design, procurement and production environments. 
Identification of deviations are also conducted four times between actual performance and the respective goal which indicates the problems and hence decision is needed. As four different specific environments are scanning, then setting business and manufacturing performance goal, identifying decision problems, establishing decision problems ownership and constructing formal problem statements are become more complex and complete.

In the next stages which are development of perspective preference and mental model, design decision model and evaluate choice, and the implementation of decision stage, all have the same procedure as stage 1 . In each stage, instead of only consider one environment, it consider four environments.

The second stage is development of perspective preference and mental model. In this stage, the development is based on the expertise contributions of each manufacturing entities from four different environments and these contributions bring four new perspectives to the creation of goals, alternatives and constraints. The understanding of more manufacturing problems and participants perspectives which includes all environment on the problems form a more complete mental model that suggest what kind of information and data should be analysed, to what extend and with which method in each environment. This mental model is evolved as more perspectives developed.

After that, stage of design decision model and evaluate choice is discussed. In this stage, design phase focus on the simplification of all manufacturing environment in CMN and conceptualising decision problems in order to developing models that can be analyse alternatives for decision solution. The choice phase in the mean time compares all potential solution from four environments based on the decision models and justifies organizational resources for implementation recommended solution.

The last stage discussed is implementation of decision outcome. In this stage, implementation means to physically execute manufacturing activities in accordance to the recommended outcomes.

\section{Conclusion}

It has been discussed the formation of relationship mapping among participants in collaborative manufacturing network. This mapping is used as a basis to define new comprehensive business model in CMN context. The last part of this paper is the development of decision making process for the new CMN model which is previously defined.

\section{References}

[1] Choy KL, Lee WB, Lo V. An enterprise Collaborative management system - a case study of supplier relationship management. The Journal of Enterprise Information Management. 2004; 17(3): 191-207.
[2] D'Amours S, Lefrancois P, Montreuil B, Ramudhin A. Unquality costing sampling plans by variables and their implications on supply relationships. International Journal of Production Economics. 1993; 32: 315-326.

[3] Bareduan SA, Hasan S, Ariffin S. Finite scheduling of collaborative design and manufacturing activity: a Petri net approach. 2008; 19(2): 274-288.

[4] Wang Q. Artificial neural networks as cost engineering methods in a collaborative manufacturing environment. International Journal of Production Economics. 2007; 109: 53-64.

[5] Perrin O, Wynen F, Bitcheva J, Godart C. A Model to Support Collaborative Work in Virtual Enterprises. in Proceedings of the International Conference of business Process management. Eindhoven. The Netherlands: Springer-Verlag. 2003.

[6] Chan HK, Chan FTS, Samaranayake P. Adaptive Make-to-Order Strategy in Distributed Manufacturing Supply Chains. in Proceedings of the 3rd IEEE International Conference on Industral Informatics. (INDIN). 2005.

[7] Rudberg M, West BM. Global operations strategy: Coordinating manufacturing networks. The International Journal of Management Science. 2008; 36: 91-106.

[8] Clarke N. The relationships between network commitment, its antecedents and network performance. Management Decision. 2006; 44(9): 1183-1205.

[9] Danilovic M, Winroth M. A tentative framework for analysing integration in collaborative manufacturing network settings: a case study. Journal of Engineering and Technology Management. 2005; 22: $141-158$.

[10] Noori H, Lee WB. Dispersed network manufacturing: adapting SMEs to compete on the global scale. Journal of Manufacturing Technology Management. 2006; 17(8): 1022-1041.

[11]Coughlan P, Coghlan D, Lombard F, Brennan L, McNichols T, Nolan R. Managing collaborative relationships in a period of discontinuity. International Journal of Operations \& Production Management. 2003; 23(10): 1246-1259.

[12]Shi YJ, Gregory M. Winning a Faster Global Business Growth on a New Entrepreneurial Collaborative Network. IEEE. 2004,

[13]Ren Z, Hassan TM, Anumba CJ. The engineering services of a universal e-Engineering Hub: Application to the construction industry. Advances in Engineering Software. 2008; 39: 545557.

[14]Bititci US, Martinez V, Albores P, Parung J. Creating and managing value in collaborative networks. International Journal of Physical Distribution \& Logistics Management. 2004; 34(3/4): 251-268.

[15]Ito T. Whiteboard-based interface for collaboration in emanufacturing environment. Journal of Manufacturing Technology Management. 2007; 18(1): 25-35.

[16] Australian Government, Department of Industry, Tourism and Resources. Making It Globally: Advanced Manufacturing Action Agenda. viewed 2 March 2009, <http://www.industry.gov.au/amaa〉. 2006

[17]Johansen K, Comstock M, Winroth M. Coordination in collaborative manufacturing mega-networks: A case study. 2005; 22: 226-244.

[18]Winroth M, Danilovic M. Linking Manufacturing Strategies to Design of Production Systems in Collaborative Manufacturing Networks. in Proceedings of the 14th Annual Conference of the Production and Operations Management Society. Savanna. Georgia. USA. 2003.

[19] Anumba CJ, Ugwu OO, Newnham L, Thorpe A. A multi-agent system, for distributed collaborative design. Logistics Information Management. 2001: 14(5/6): 355-366.

[20]Cil I, Alpturk O, Yazgan HR. A new collaborative system framework based on a multiple perspective approach: InteliTeam. Decision Support Systems. 2005; 39: 619-641.

[21]Wang D, Nagalingam SV, Lin GCI. Development of an agent-based Virtual CIM architecture for small to medium manufacturers. Robotics and Computer-Integrated Manufacturing. 2007; 23: 1-16. 
[22] McClellan, M. Collaborative manufacturing: A strategy built on trust and cooperation. 2003; 12. Control Solutions International.

[23] Nagalingam S. A Holistic Model for a Collaborative Manufacturing Network. Internal Document. University of South Australia. Australia. 2008

[24]Freeman S, Cray D, Sandwell M. Networks and Australian professional services in newly emerging markets of Asia. International Journal of Service Industry Management. 2007; 18(2): 152-166.

[25] Jack S L. Approaches to studying networks: Implications and outcomes, Journal of Business Venturing. 2008.

[26] Montreuil B, Frayret JM, D'Amours S. A strategic framework for networked manufacturing. Computers in Industry. 2000; 42: 299-317.

[27] Mesa International. Collaborative Manufacturing Explained. www.mesa.org. 2004.

[28]ARC Advisory Group. Collaborative Manufacturing Management Strategies. Thought Leaders for Manufacturing \& Supply Chain. 2002.

[29]Ramudhin A, Montreuil B, Lefranois P. Scheduling project activities in a distributed environment. European Journal of Operational Research. 1994; 78: 242-251.

[30] Frayret JM, D'Amours S, Montreuil B, Cloutier L. A network approach to operate agile manufacturing systems. International Journal of Production Economics. 2001; 74: 239-259.

[31]Fujimoto H. Collaborative networking in a multi-stage industrial channel. International Journal of Physical Distribution \& Logistics Management. 2003; 33(3): 229-235.

[32] Bolduc MC, Renaud J, Montreuil B. Synchronized Routing of Seasonal Products through a Production/Distribution Network. CEJOR. 2006; 14: 209-228.

[33] Cloutier L, Frayret JM, D'amours S, Espinasse B, Montreuil, BT. A commitment-oriented framework for networked manufacturing coordination. International Journal of Computer Integrated Manufacturing. 2001; 14(6): 522-534.

[34] Sherer SA. Critical Success Factors for Manufacturing Networks as Perceived by Network Coordinators. Journal of Small Business Management. 2003; 41(4): 325-345.

[35] Lin HW, Nagalingam SV, Chiu M, Lin GCI. Development of a Webbased Three-tier Decision Support System for Virtual Enterprises,
Flexible Automation and Intelligent manufacturing. FAIM2004. Toronto, Canada. 2004.

[36] Tomkins C. Interdependencies, trust and information in relationships, alliances and networks. Accounting, Organizations and Society. 2001; 26: 161-191.

[37]Palakshappa N, Gordon ME. Collaborative business Relationships Helping firms to acquire skills and economies to prosper. Journal of Small Business and Enterprise Development. 2007; 14(2): 264-279.

[38] Vallespir B, Kleinhans S. Positioning a company in enterprise collaborations: vertical integration and make-or-buy decisions. Production Planning \& Control. 2001; 12(5): 478- 487.

[39]Danilovic M. Bring your suppliers into your projects-Managing the design of work packages in product development. Journal of Purchasing \& Supply Management. 2006; 12: 246-257.

[40] Yam AYK, Chan MFS, Chung WWC. Networked enterprise: a case study of implementing an information network system for global product development. Benchmarking: An International Journal. 2007; 14(3): 369-386

[41]Shi Y, Gregory M. International manufacturing networks-to develop global competitive capabilities. Journal of Operations Management. 1998; 16: 195-214

[42]Evan JR, Lindsay WM. Managing for Quality and Performance Excellence. $7^{\text {th }}$ Ed. Thomson South-Western. USA. 2008.

[43] Technology Partnerz. Enterprise Relationship Management Overview, $\begin{array}{llll}\text { viewed } & 1 & \text { june }\end{array}$ <http://www.technologypartnerz.com/eng/erm.asp>. (2008),

[44] Timings R. Basic Mnaufacturing, $3^{\text {rd }}$ edition. Newnes. An imprint of Elsevier. Barlington. MA. 2004.

[45]Poler R, Hernandez JE, Mula J, Lario FC. Collaborative forecasting in networked manufacturing enterprises. Journal of Manufacturing Technology Management. 2008; 19(4): 514-528.

[46]Courtney JF. Decision making and knowledge management in inquiring organizations: toward a new decision-making paradigm for DSS. Decision Support Systems. 2001; 31: 17-38.

[47]Lee WB, Lau HCW. Multi-agent modelling of dispersed manufacturing networks, Expert Systems with Applications. 1999; 16: 297-306.

[48]Lin HW. Development of a Global Decision Support System towards Collaborative Manufacturing and Virtual Manufacturing. $\mathrm{PhD}$ Thesis. University of South Australia. Australia. 2008 